\title{
Sex Differences in Bone Resorption: A Scanning Elec- tron Microscopic Study of Mouse Parietal Bones
}

\author{
Kazuhiro ABE, Taiki Kanno, Kenji Kitao and Gary B. Schneider \\ Department of Anatomy (Prof. T. ITo), Hokkaido University School of Medicine, Sapporo, Japan and
} Department of Anatomy, Loyola University Medical Center, Maywood, Illinois, U. S. A.

Received February 24, 1984

Summary. Bone resorption surfaces formed by osteoclasts can be identified as rough areas by scanning electron microscopy (SEM). Iu this study, the endocranial surfaces of mouse parietal bones were examined by SEM at $1,4,6,8,14$ and 20 weeks of age in an attempt to understand the bone resorbing activity after the cessation of bone growth.

On the inner surface of the parietal bones, the rough areas, composed of a group of 8 to $30 \mu \mathrm{m}$ wide concavities, can be divided into two distinct groups (type I and type II). The surface of type I areas appeared irregularly rough and those of type II revealed feather, fire-flame, or wave-like patterns due to characteristic arrangements of the concavities.

The rough areas occupying the inner surface of the parietal bones made up about $60 \%$ of the surface area at 1 week and about $5 \%$ at 4 weeks in both sexes. The rough areas were all type $I$ at this age. After puberty, the rough areas in males occupied about $10 \%$ of the inner surface until 20 weeks and consisted of large type I and small type II areas. In females, the proportion of the rough areas increased after puberty and occupied about $40 \%$ of the endocranial surface at 14 and 20 weeks. The type $I$ areas were much larger, increasing in size with age and eventually occupying a large proportion of the rough areas. The sex differences in the rough areas were reversed by gonadectomy.

The results suggest that male and female gonadal products, possibly sex hormones, have respective inhibitory and stimulatory effects on the formation of bone resorptive surfaces, and may be responsible for the sex differences in the size and morphological features of the areas on the bone surfaces.

Osteoclasts, or multinuclear giant cells seen on the surface of bones, produce indentations on the bone surface by their bone dissolving activity (see reviews by GöTHLIN and Ericsson, 1976; Parfitt, 1976 a-d; Holtrop and King, 1977; Bonucci, 1981). The indentations formed can be identified by scanning electron microscopy (SEM) (BoydE and Hobdell, 1969a, b; ANDERSon and DANYLCHACK, 1977). The flat bones of the growing skull have many osteoclasts on their endocranial surface which are responsible for changes in the curvature of the skull (BARNICOT, 1947). We have previously made use of SEM to investigate the surface of parietal bones in growing mice (ABE et al., 1983). According to our observations, the outer surface of the bone is smooth, while the inner surface consists of smooth and rough areas. The rough areas are considered to be resorption areas formed by osteoclasts. The proportion of rough areas occupying the inner surface increases from birth and reaches a maximum at one week of age as the skull is growing rapidly. The proportion of rough areas decreases with the 
decreasing growth rate and becomes very small until 3 to 4 weeks when growth ceases altogether.

The changes in size and shape of bones produced by bone formation and resorption during growth is known as modeling (PARFITT, $1976 \mathrm{a}, \mathrm{d}$ ). The changes in the proportion of rough areas on the inner surface of the skull bones is considered to be related to the modeling of these bones. However, after skull growth has ceased, the surface of bones continues to remodel through a bone replacement process, by bone resorption and formation (PARFITT, $1976 \mathrm{a}, \mathrm{d}$ ). In this study, we further examined the surface of the parietal bones in adult mice by SEM in an attempt to understand the bone resorption involved in this remodeling, and found significant sex differences in the size of the resorption surfaces. The effects of gonadectomy on the sex differences and the number of osteoclasts demonstrating acid-phosphatase activity were also studied.

\section{MATERIALS AND METHODS}

In this study, 121 dd-mice of both sexes were used. For scanning electron microscopy (SEM), 85 mice were killed at 1, 4, 6, 8, 14 and 20 weeks of age. The calvaria was removed, freed of the periostium and dura by using a fine forceps and a small rubber policeman under the the dissecting microscope, and immersed in 5\% sodium hypochloride for 15 to $30 \mathrm{sec}$ to remove organic material. The bone was washed with water, dehydrated in acetone, air-dried, attached on an alminium stub, coated with gold using an ion-coater, and observed by SEM.

For quantitative observations, photographs covering the entire area of the inner surface of the parietal bones were taken at $50 \times$, and the outlines of the bone and resorption areas were traced on paper, cut, and weighed to obtain the size of the bone resorption areas.

Gonadectomy study: Twenty six mice of both sexes were gonadectomized at 4 weeks of age and killed at 14 weeks of age for SEM.

Osteoclast count: Ten untreated mice of both sexes were killed at 14 weeks of age. The calvaria was fixed in $5 \%$ formalin- $0.1 \mathrm{M}$ cacodylate buffer $(\mathrm{pH} 7.4)$ for $1 \mathrm{hr}$. After removing the periostium and dura, the calvaria was washed with buffer, incubated in a medium for $1 \mathrm{hr}$ for detection of acid-phosphatase by the azo-dye method (BARKA and Anderson, 1963), and mounted in water or glycerin jelly. The distribution and number of osteoclasts on the parietal bones were examined by light microscopy.

The statistical significances of the differences between the values obtained were evaluated by the Student's t-test.

\section{RESULTS}

The inner surface of parietal bones consisted of smooth and rough areas. At 1 week of age, the central region of the inner bone surface was occupied by a large rough area (Fig. 1, 2). Around the large rough areas, small, round or oval rough areas were scattered: the smallest being about $40 \mu \mathrm{m}$ wide. The peripheral surface of the parietal bones showed a rim of smooth surface surrounding the large central area. There were also small smooth areas within the rough zone in the central region of the bone surface (Fig. 2).

The rough areas were composed of a group of shallow irregular concavities, oval 

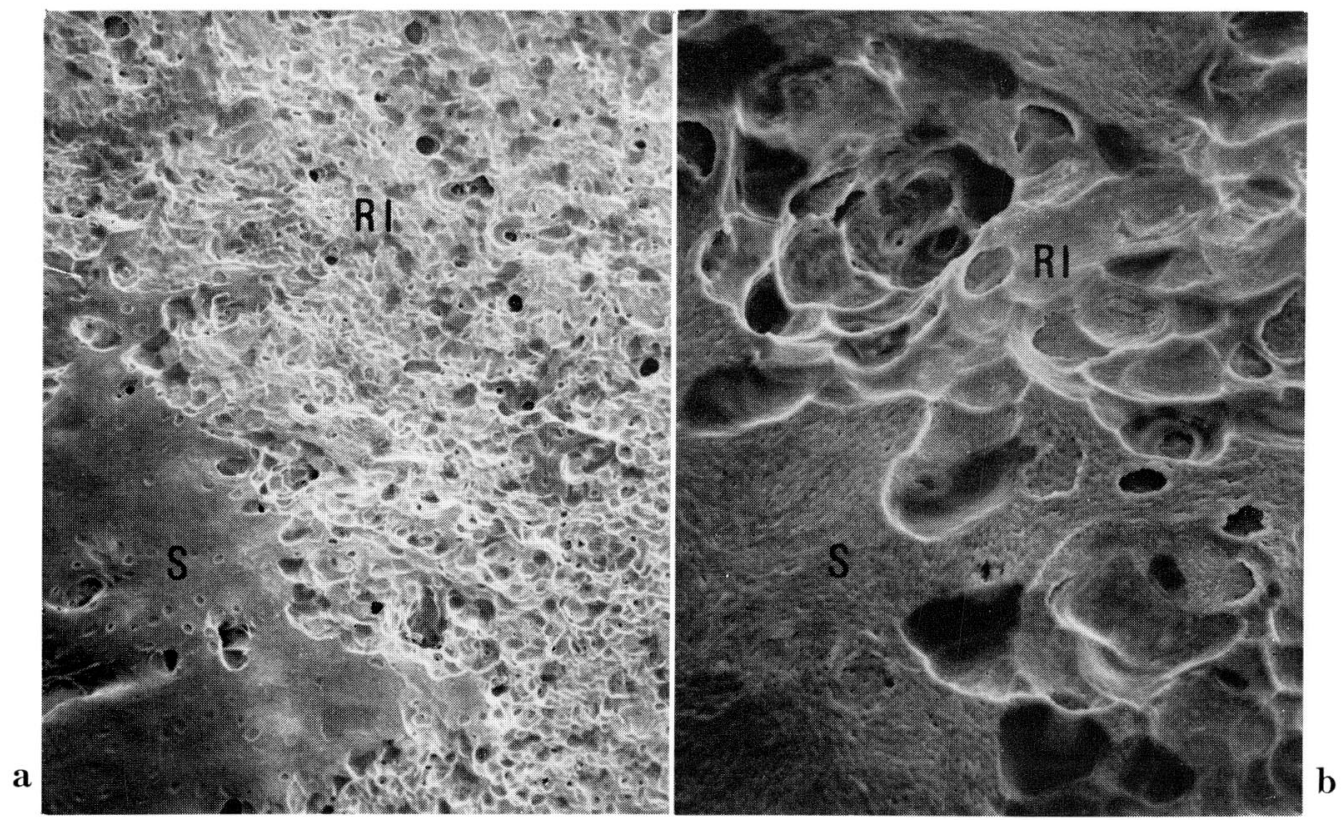

Fig. 1. a and b. Inner surface of the parietal bone at 1 week of age. $S$ smooth area, RI type I rough area. a. Surface of type I rough area appears irregularly rough without any remarkable pattern. $\times 90$. b. The concavities of the type I rough area look like spoon-cut concavities. $\times 450$

or polygonal in shape, measuring 8 to $30 \mu \mathrm{m}$ wide (Fig. 1b). The borders between adjacent concavities appeared as low but quite distinct ridges. The concavities looked like spoon-cut concavities (Fig. 1b). The bottom of each concavity was either fibrous, granular, or smooth. Concavities of varying size and shape were irregularly intermingled. Thus, SEM showed the surface of the rough areas as irregularly rough without any remarkable pattern (Fig. 1a). These rough areas were classified as type I to distinguish them from the type II rough areas with characteristic patterns which were seen in the adult mice.

The peripheral margin of the rough areas was clearly deliniated from the surrounding flat, smooth areas, and showed irregular bay-like configurations due to the peripheral concavities (Fig. 1b).

At 4 weeks of age, the inner surface was mostly occupied by smooth areas and had scanty rough areas which were small in size and similar in appearance to those described above (Fig. 2).

After 6 weeks, the rough areas increased again in proportion, especially in female mice (Fig. 2). At 14 and 20 weeks of age, the inner surface of the parietal bones showed several scattered rough areas which often occupied a larger proportion of the surface than the smooth areas. The rough areas were irregular in shape and distribution as compared with those at 1 week. Some of the rough areas tended to be located close to the peripheral margin of the bone. Small, irregular rough areas were often located at the openings of vascular canals.

The rough areas observed after 6 weeks were classified into two types according to their appearance by SEM (Fig. 3). Type I rough areas were those seen in mice at 1 


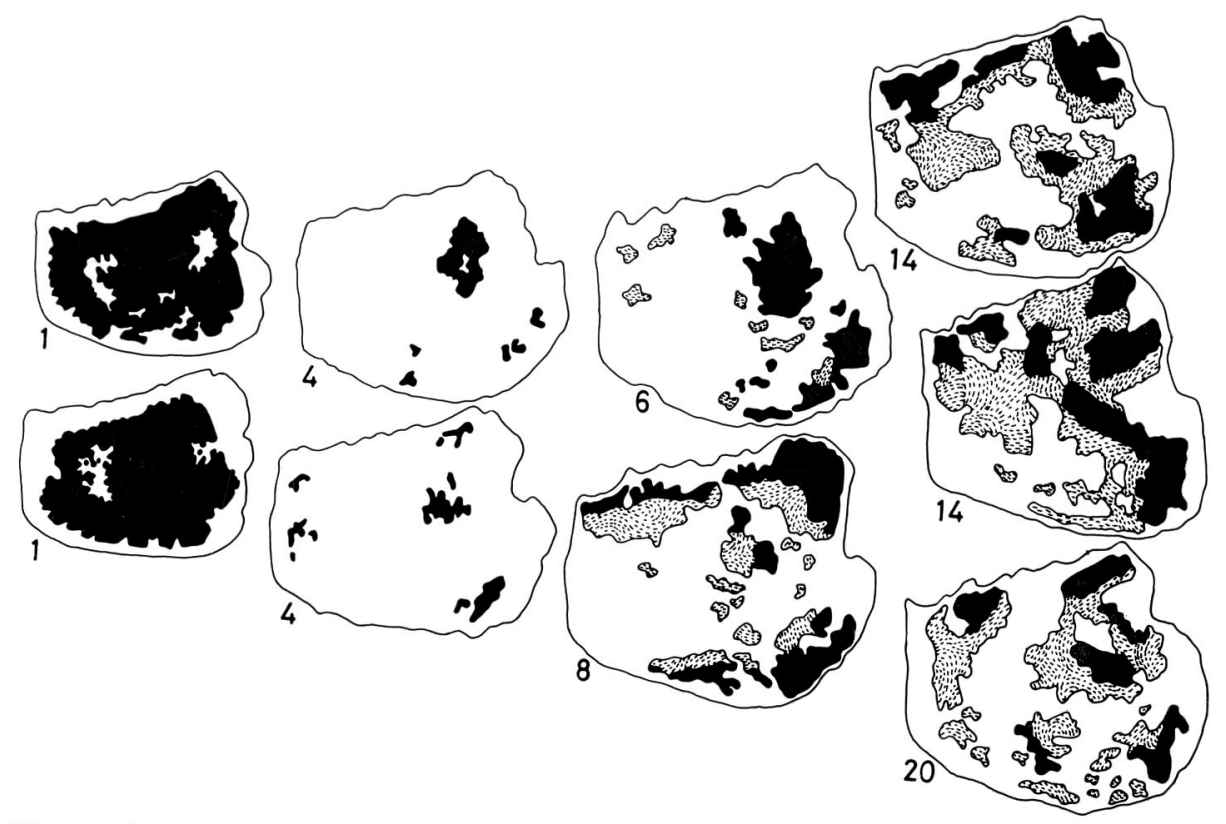

Fig. 2. Drawings representing the distribution of smooth areas (white) and rough areas of type I (black) and type II (shaded) on the inner surfaces of the parietal bones in female mice at $1,4,6,8,14$ and 20 weeks of age. Upper and left edges of each parietal bone direct to the frontal and sagittal suture, respectively. Male mice from 6 to 20 weeks show surfaces similar to ones in females at 6 weeks of age. $\times 6$

and 4 weeks of age, as described above. Type II showed feather, fire flame, or wavelike patterns by SEM at low magnifications because of their characteristic arrangement of concavities (Fig. 3, 4). The concavities making up the rough areas were more irregular in size and shape than those of type I. Many of them were elongated and arranged in a similar direction in groups to produce the characteristic patterns. The concavities were usually shallow and bounded by ridges not as distinct as those in type I (Fig. 5). The bottom of each individual concavity appeared similar to those in type I, and the fibers at the bottom occasionally showed cut-faces of collagen bundles (Fig. 5).

Morphologically different rough areas occasionally merged into a single large rough area (Fig. 2, 3 a, c). Small rough areas were usually made up of a single type. Small rough areas at the openings of vascular canals were type II (Fig. 4). On the inner surfaces showing large rough areas, type II predominated (Fig. 2).

In male mice after 6 weeks of age, the inner surface of parietal bones appeared similar to those in females at 6 weeks of age. The rough areas were small and mainly type I, but small type II areas were also seen.

The outer surface of the bones from infantile to adult mice was covered mainly with smooth areas, and rough areas were very rare.

Quantitative observations: The proportion of rough areas occupying the inner surface was about $60 \%$ at 1 week of age. This decreased to about $5 \%$ at 4 weeks of age (Fig. 6). There was no sex difference at 1 and 4 weeks. After 6 weeks, the proportion of rough areas in female mice increased to about 40\% (ranging 25-60\%) at 14 and 20 weeks (Fig. 6). In male mice, the proportion was about $10 \%$ from 6 to 20 weeks (ranging 5-20\% at 14 and 20 weeks) (Fig. 6). Thus, the proportion of the rough areas 
occupying the inner surface revealed significant sex differences after 8 weeks $(\mathrm{P}<0.005$ at 8 weeks, and $\mathrm{P}<0.001$ at 14 and 20 weeks).

As seen in Figure 7, the rough areas at 1 and 4 weeks were all type I in both sexes. After 6 weeks, in addition to type I, type II areas appeared in both sexes. In female mice, type II areas increased in proportion with increasing rough areas on the inner

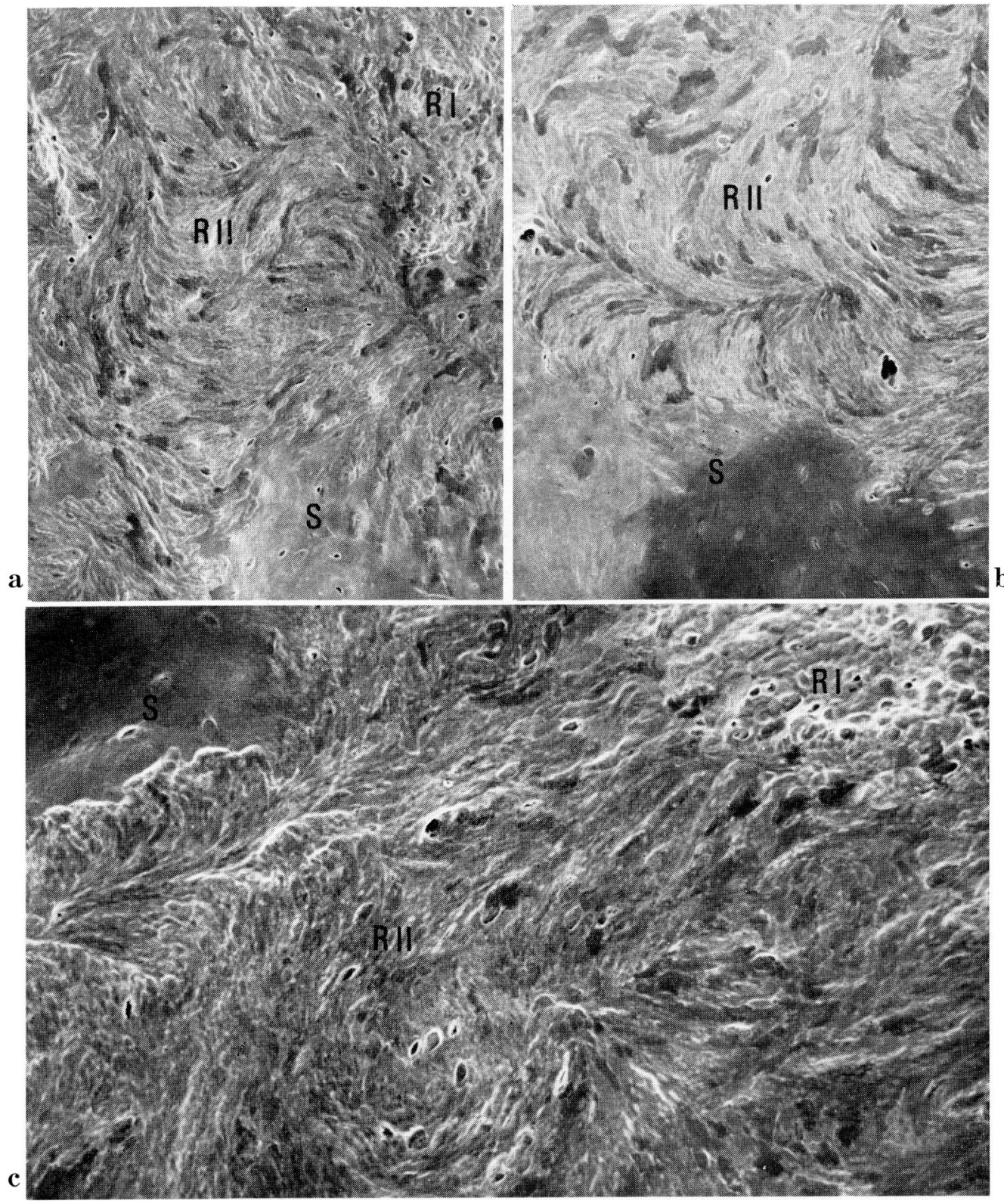

Fig. 3. a-c. Inner surface of the parietal bone in adult mice. $S$ smooth area, $R I$ type I rough area, RII type II rough areas. Type I rough areas show irregular surfaces. Type II rough areas represent feather, fire flame, or wave-like patterns. a: 14 weeks of age. $\times 100$. b: 14 weeks of age. $\times 140$. c: 8 weeks of age. $\times 190$ 
surface. At 14 and 20 weeks, type II areas occupied as much space as type I areas. The increase in proportion of the rough areas after 6 weeks appeared to be due to the increase in type II areas. On the other hand, in male mice, type II areas were consistently smaller when compared with type I areas. To summarize, in adult mice,
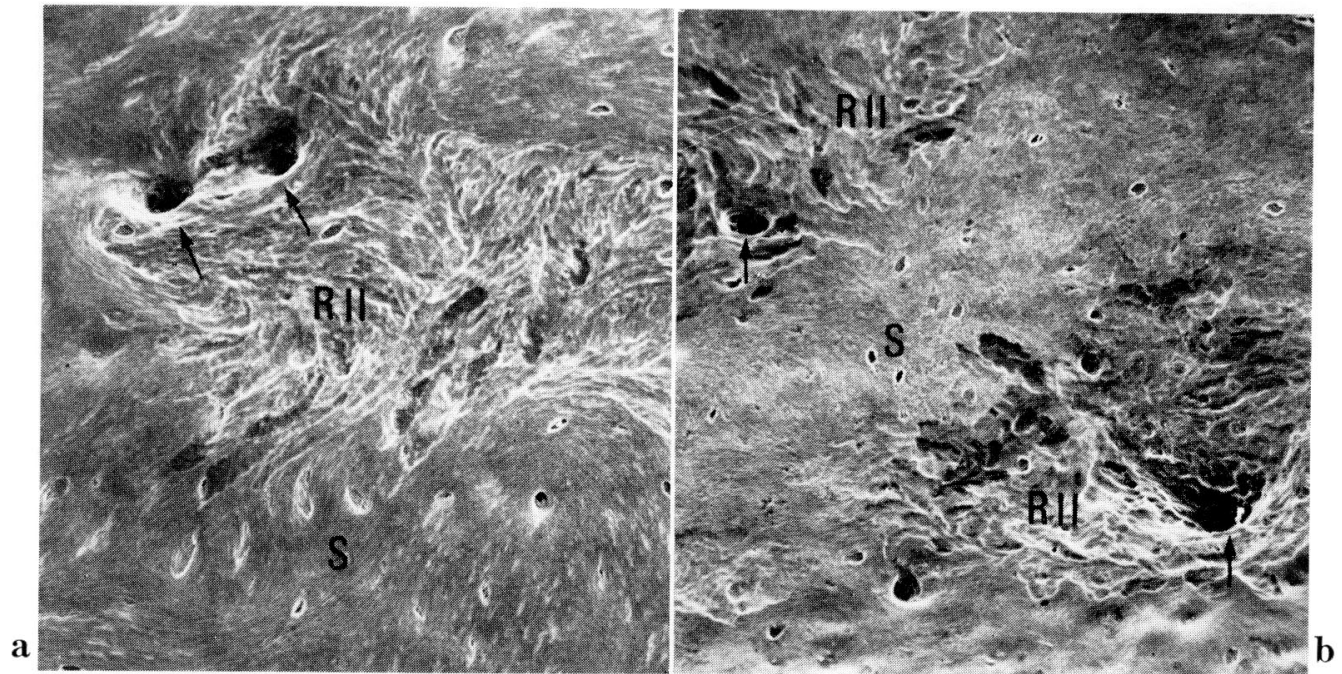

Fig. 4. $\mathbf{a}$ and $\mathbf{b}$. Inner surface of the parietal bone in adult mice at 8 weeks of age. Rough areas at the openings of vascular canals (arrows) are type II (RII). S smooth area. $\mathbf{a}: \times 150, \mathbf{b}$ : $\times 140$
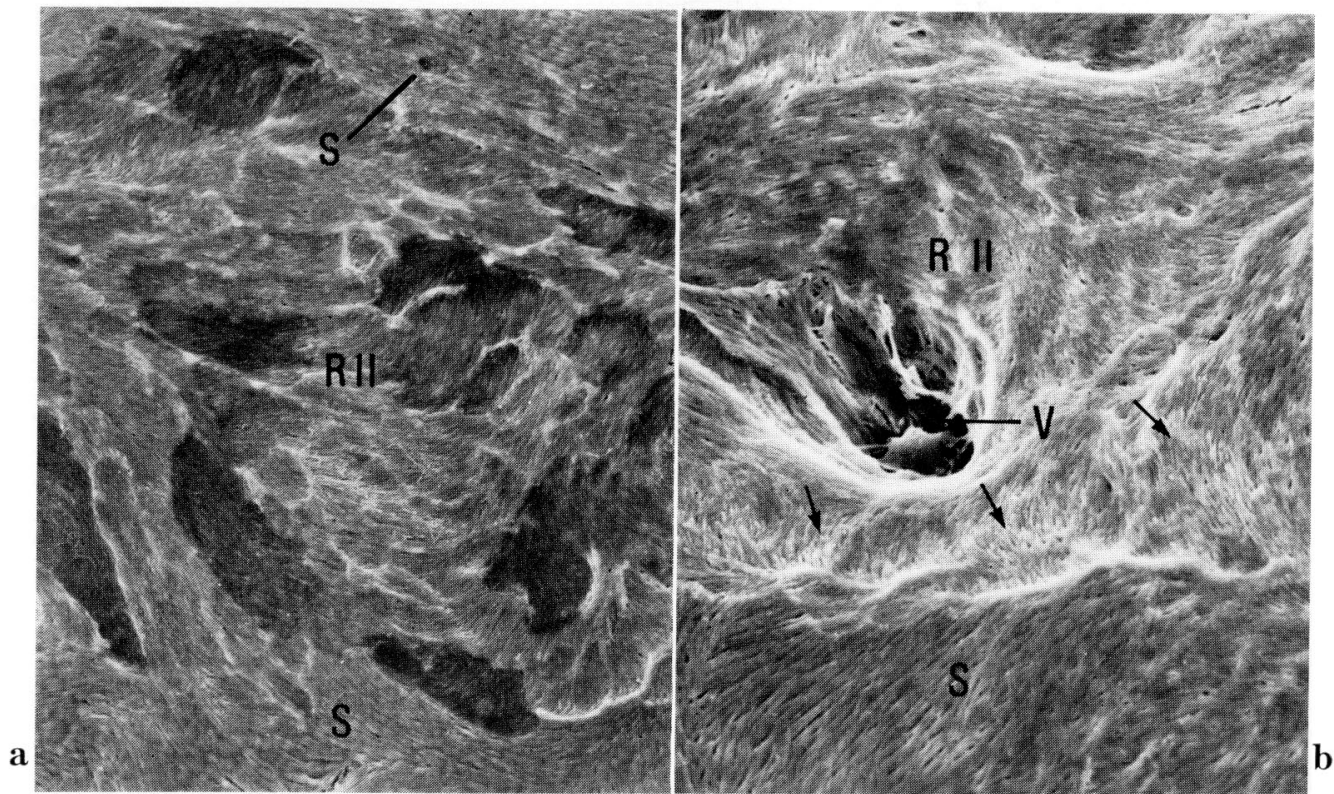

Fig. 5. $\mathbf{a}$ and b. Inner surface of the parietal bone in adult mice. $S$ smooth area, RII type II rough area. Concavities of $R I I$ are shallow and bounded by obscure ridges. Cut faces of collagenfiber bundles are seen in the rough area (arrows). $V$ vascular canal. a: 14 weeks of age. $\times 500, \mathbf{b}: 8$ weeks of age. $\times 700$ 


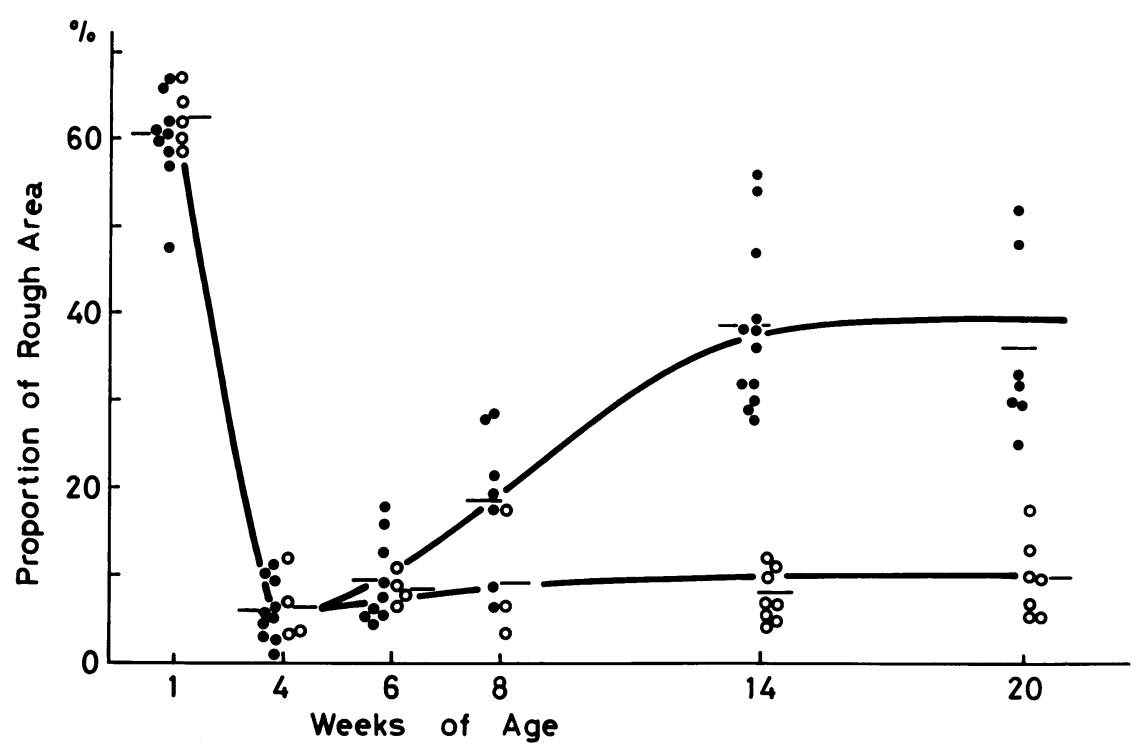

Fig. 6. Proportion of the rough areas occupying the inner surface of the parietal bone at various weeks of age. Round dot female, circle male. Bars represent mean values.

type II areas occupied significantly larger areas in females than in males $(\mathrm{P}<0.001)$.

Effects of gonadectomy: In mice at 14 weeks of age, the proportion of the rough areas occupying the inner surface of the parietal bone was significantly larger in females than in males $(\mathrm{P}<0.001)$ (Fig. 8). Gonadectomized females showed a smaller proportion of the rough areas than normal females $(\mathrm{P}<0.001)$; the rough areas in gonadectomized females covered a small proportion of the surface, similar to those in normal males (Fig. 8). In gonadectomized males, the proportion of rough areas was larger than that in the normal males $(\mathrm{P}<0.001)$ and approached the value in normal females (Fig. 8). Thus, the sex difference in the proportion of the rough areas occupying the inner surface in gonadectomized mice was reversed from that of the normal specimens; the proportion of rough areas was greater in the gonadectomized males than in the gonadectomized females $(\mathrm{P}<0.005)$. In addition, type II areas were small in the gonadectomized females and enlarged in the gonadectomized males.

Number and distribution of osteoclasts: After the cytochemical reaction for acidphosphatase activity by the azo-dye method, osteoclasts could be identified by light microscopy as red-stained giant cells extending dendritic processes on the bone surface (Fig. 9). In female mice at 14 weeks, osteoclasts were accumulated in several regions of the inner surface, whereas in male mice osteoclasts were small in number. There were twice as many osteoclasts in females as in males $(\mathrm{P}<0.005)$ (Fig. 10).

\section{DISCUSSION}

In this study we observed two types of rough areas on the bone surface. Type I in young mice, as detailed previously (ABE et al., 1983), is undoubtely considered to be formed by bone resorbing activities of osteoclasts. Adult mice possessed type II rough areas in addition to type I. Concavities consisting of type II differ in shape and 
arrangement from those of type I but appeared similar in details to those of type I. Type II rough areas are also considered to be due to bone resorption. Furthermore, acid-phosphatase positive osteoclasts appeared to be distributed on the rough areas in the adult mice.

The bone resorption, especially involved in the modeling of bones, is closely related to the growth of bones. In mice, the skull as well as the brain grows rapidly for the

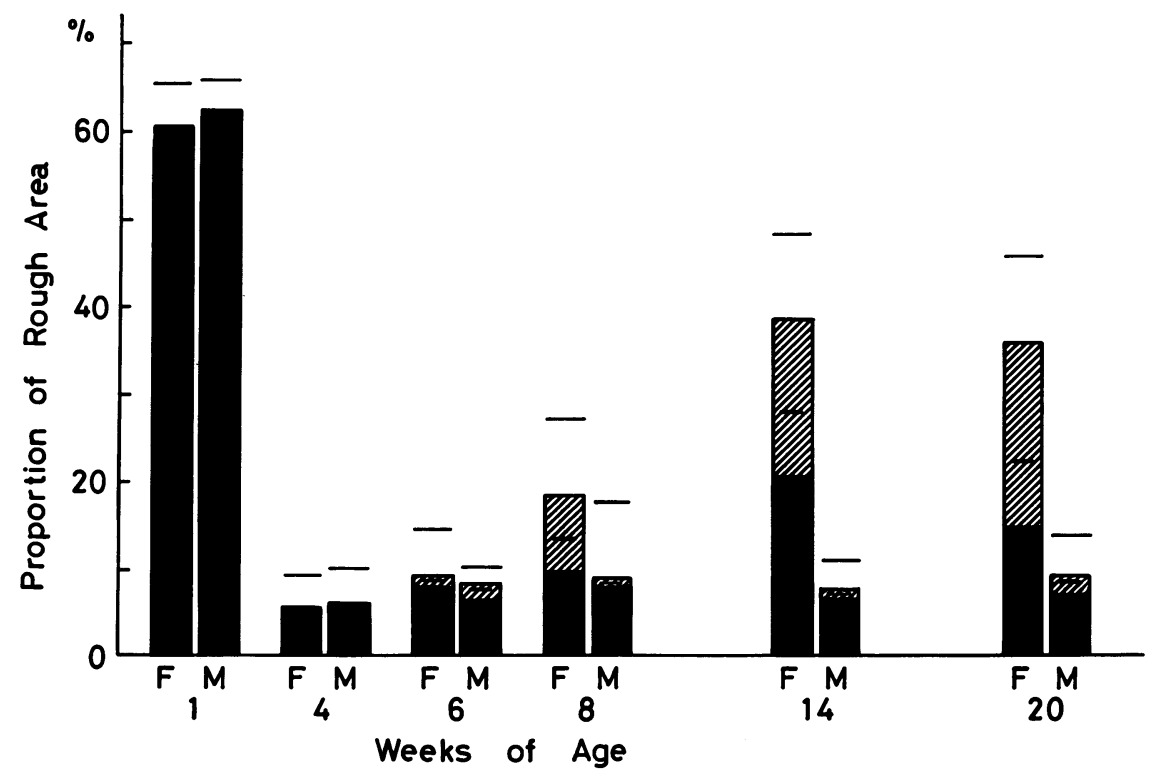

Fig. 7. Proportion of type I (black column) and type II (shaded column) rough areas on the inner surface of parietal bone at various weeks of age. The bar above each column shows the standard deviation (SD) of the total rough areas, and the bar in each column is the SD of type I rough areas, which is the same SD as type II rough areas. $F$ females, $M$ males.

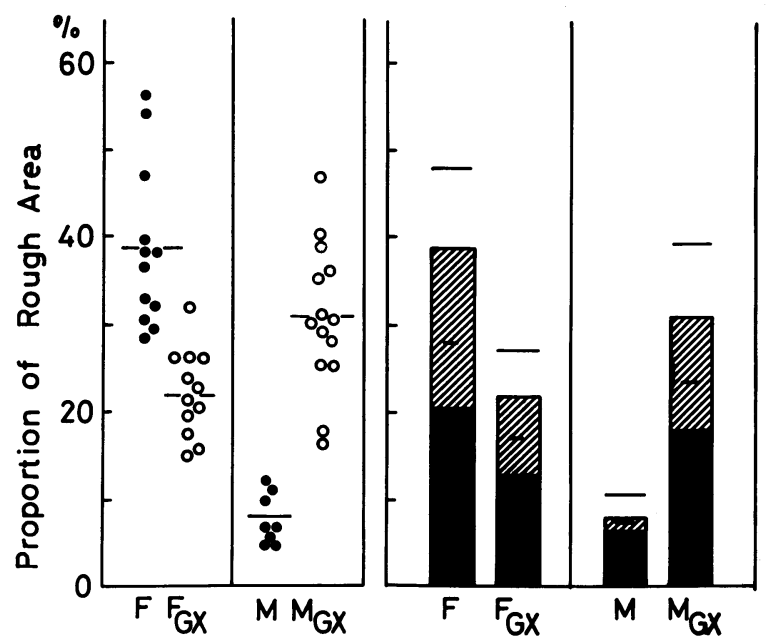

Fig. 8. Proportion of rough areas on the inner surface of parietal bones at 14 weeks of age. $F$ and $M$ females and males, $F_{G X}$ and $M_{G X}$ gonadectomized females and males. The left represents values with means (bars) and the right shows the mean and SD of type I (black column), type II (shaded column), and the total rough areas (bar $\mathrm{SD}$ ). 


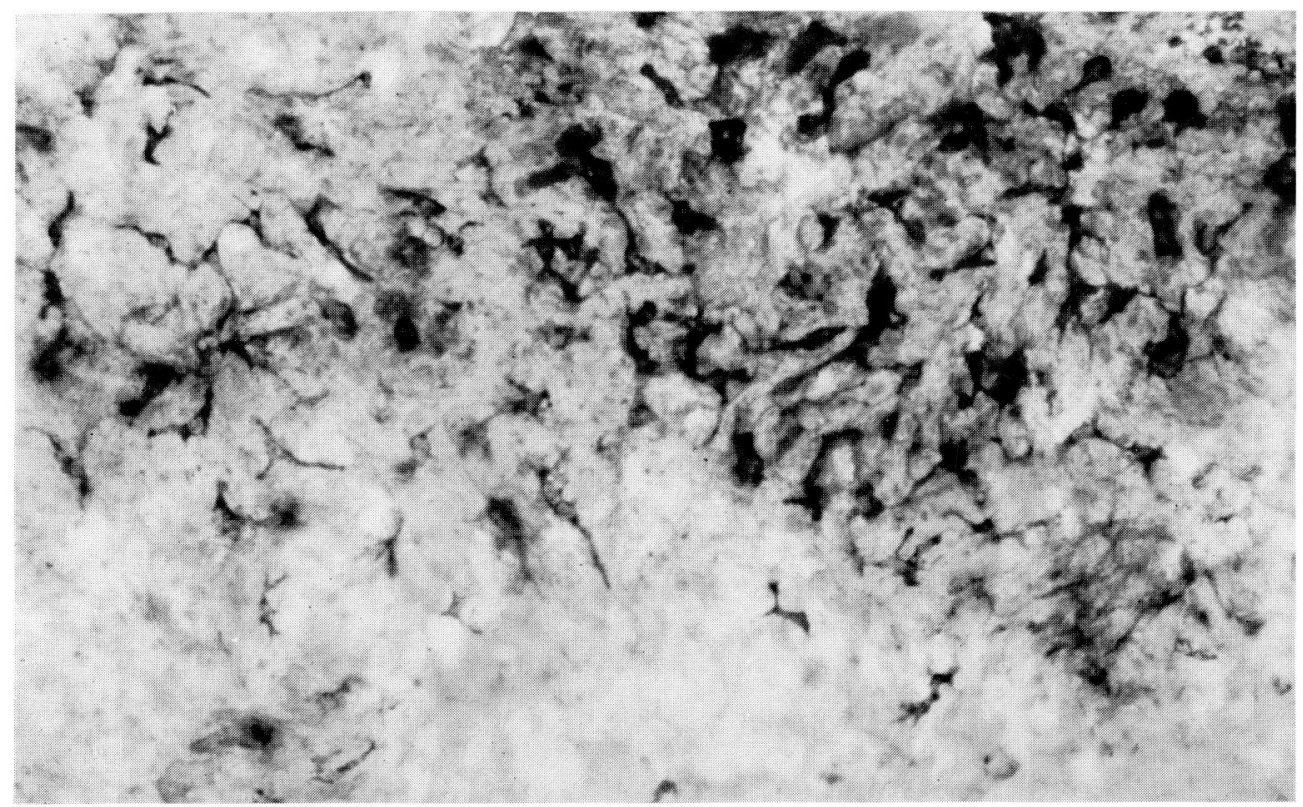

Fig. 9. Light micrograph showing acid-phosphatase positive osteoclasts on the inner surface of the parietal bone at 14 weeks of age. Osteoclasts with dendritic processes are more densely accumulated at the upper right region. The lower region has few osteoclasts. $\times 100$

first week after birth. Then the growth rate gradually decreases until 3 weeks when the growth stops (ABE et al., 1983). On the inner surface of the parietal bones in growing mice, the variance in the number of osteoclasts and the proportion of the surface involved in bone resorption almost paralleled the changes in growth rate of the skull (ABE et al., 1983). The changes in resorptive areas can be interpreted to be the result of bone modeling for the enlargement of the cranial vault, due to osteoclastic activities to make the room for the growing brain.

In adult mice after the cessation of skull growth, resorption areas are to be expected in small proportions because of remodeling in which only a small fraction of the bone surface is actively exchanged (PARFITT, 1976a, d). However, this was not the case.

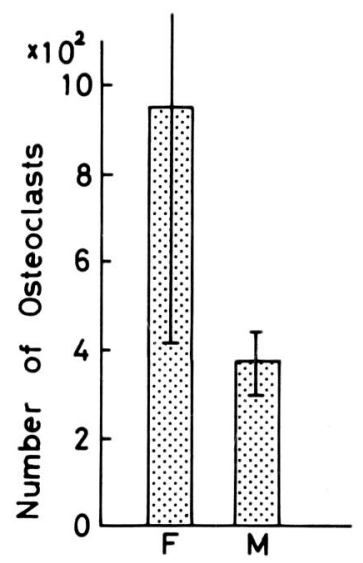

Fig. 10. Number (mean and SD) of osteoclasts on the inner surface of parietal bones at 14 weeks of age. $F$ females, $M$ males.

After the initial high level was followed by a decline, the proportion of rough areas on the inner surface of the cranial bones increased again to about two thirds of the value at 1 week of age (peak value during growth) in female mice but remained low in male mice. Thus, the total size of resorption areas in adult mice revealed a significant sex difference.

Little is known about sex differences in the normal skeletal system. The sex 
differences may be attributed to the effect of sex hormones on bone. In this relation, the effects of estrogen on skeletal homeostasis have been studied for bone formation and resorption (seen reviews by PARFITT, 1976 b-d). Especially noteworthy is the fact that osteoporosis, a disorder due to excess bone resorption, is known to be more common in postmenopausal women than older men, and estrogens have been implicated in the supression of bone resorptive activity (Dunnill et al., 1967; Hossain et al., 1970). Therefore, postmenopausal women may show increased bone wasting, resulting in osteoporosis, and postmenopausal osteoporosis is treatable with estrogen (REIFENSTEIN 1957; Hossain et al., 1970; Gallagher and Nordin, 1972). The effect of estrogen on bone resorption has also been proven experimentally; in a tissue culture system, PTH (parathyroid hormone)-induced bone resorption can be blocked by estrogen (ATKINS et al., 1972); and ovariectomized rats demonstrate an increased sensitivity to PTH (Orimo et al., 1972). However, models of osteoporosis could be produced by gonadectomy in male rats as well as female rats (SAville, 1969; Wink and Felts, 1980). Androgen also appears to inhibit the bone resorption though androgen may be less effective than estrogen.

In our study, the sex differences became apparent after puberty, at 5 to 6 weeks of age. The increase in rough areas in females was prevented by ovariectomy. Thus, the presence of the ovary or possibly estrogen appeared to increase bone resorptive activity. This is similar to the effects of corticosteroid which can induce osteoporosis clinically and experimentally (STOREY, 1963; PARFITt, 1976d) but opposed to the generally accepted concept that estrogen supresses bone resorptive activity. The supressive effects of estrogen on bone resorption have been considered from studies on postmenopausal osteoporosis, as descrived above. On the other hand, in male mice, there was no obvious increase in bone resorption after puberty, and androgenic hormones seem to be ineffective with respect to bone resorption. But, after gonadectomy in males, the bone resorptive areas were significantly increased. This suggests that androgens may suppress bone resorption, which is compatible with the results by WINK and FelTs (1980) who demonstrated that gonadectomized male rats became osteoporotic. From the sex differences shown in our study, it may be that estrogenic and androgenic hormones have opposite effects, the former stimulatory and the latter inhibitory, on bone resorption.

The bone resorptive areas observed after puberty are considered to reflect bone remodeling, i.e., bone replacement by a sequence of bone resorption and formation which are balanced; there is no net change in the amount of bone at the location where remodeling has occurred (PARFITT, 1976a, d). The size of resorptive areas may be an indicatoin of the rate of bone remodeling. It is probable that, in females which show large resorption areas, bone formation is also accelerated. In fact, active bone formation during growth is associated with active bone resorption (ABE et al., 1983), PTH can stimulate osteoblasts as well as osteoclasts (McGuIRE and MARKs, 1974), and estrogen administration can induce increased activity of osteoblasts (Simmons, 1963, 1966) though our study suggests that estrogenic hormone also forms large resorption areas. In addition, we observed that the size of resorption areas is significantly different between intact female and ovariectomized mice, but ORIMO et al. (1972) revealed no difference in the calcium content of bones in intact and ovariectomized rats. Thus, even if the rate of remodeling is greater in females than in males, the balance between bone resorption and formation may reveal no sex difference, as well as no difference between intact and gonadectomized animals with respect to calcium balance.

It is of interest that the rough areas in adult mice appear different from those in 
growing mice. This suggests differences between the activity of bone resorption in modeling and that in remodeling. The bone resorption results in type I rough areas during the modeling process and type I and II areas during the remodeling process. In females, the increase in the proportion of the rough areas after puberty was primarily due to the increase of type II areas. The accelerated rate of the remodeling process may result in large type II areas.

Although there has been no report to distinguish the two types of resorption areas, KREMPIEN (1979) used SEM to describe the endosteal surfaces of human femurs and observed that resorption areas from the normal bones appeared morphologically uniform and those from uremic patients with secondary hyperparathyroidism were irregular, penetrating deeply into the matrix. The resorption areas of the bone from uremic patients looked similar to the type II rough areas demonstrated in our study. This suggests that the type II rough areas may reflect an activated bone dissolving activity.

The increase in bone resorption areas may be due to an increase in the activity of osteoclasts and/or their number. Parathyroid hormone (PTH), which stimulates the bone resorption, causes an increase in the number, size and activity of osteoclasts (Tatevossian, 1973; reviews by GöThlin and Ericsson, 1976; Holtrop and King, 1977; Bonucci, 1981). In our study, osteoclasts appeared to be distributed at the site of the rough areas and their numbers showed a sex difference similar to that of rough area size. There findings suggest that the large rough areas in adult females are formed by the increased numbers of osteoclasts, but it remains to be determined if the activity of osteoclasts and/or their numbers are increased by female sex hormones.

Acknowledgements. We wish to thank the Department of Orthopedic Surgery, Hokkaido University School of Medicine, for their support in this study.

\section{REFERENCES}

Abe, K., T. Kanno and G. B. Schneider: Surface structures and osteoclasts of mouse parietal bones: A light and scanning electron microscopic study. Arch. histol. jap. 46: 663-676 (1983).

Anderson, C. and K. D. Danylchak: Scanning electron microscopic observations on bone. Arch. Pathol. Lab. Med. 101: 19-21 (1977).

Atkins, D., J. M. Zanelli, M. Peackock and R. E. C. Nordin: The effect of oestrogens in the response of bone to parathyroid hormone in vitro. J. Endocrinol. 54: 107-117 (1972).

Barka, T. and P. J. Anderson: Histochemistry. Harper \& Row, New York, 1963.

Barnicot, N. A.: The supravital staining of osteoclasts with neutral-red: their distribution on the parietal bone of normal growing mice, and a comparison with the mutants grey lethal and hydrocephalus-3. Proc. Roy. Soc. B. 134: 467-485 (1947).

Bonucci, E.: New knowledge on the origin, function and fate of osteoclasts. Clin. Orthop. 158: 252269 (1981).

Boyde, A. and M. H. Hobdell : Scanning electron microscopy of lammelar bone. Z. Zellforsch. 93: 213-231 (1969a).

: Scanning electron microscopy of primary membrane bone. Z. Zellforsch. 99: 98-100 (1969b).

Dunnill, M. S., J. A. Anderson and R. Whitehead: Quantitative histological studies on age changes in bone. J. Pathol. Bacteriol. 94: 275-291 (1967).

Gallagher, J. C. and B. E. C. Nordin : Treatment with oestrogens of primary hyperparathyroidism in postmenopausal women. Lancet 1: 503-507 (1972). 
Göthlin, G. and J. L. E. Ericsson : The osteoclasts. Review of ultrastructure, origin, and structurefunction relationship. Clin. Orthop. 120: 201-231 (1976).

Holtrop, M. E. and G. J. King: The ultrastructure of the osteoclast and its functional implications. Clin. Orthop. 123: 177-196 (1977).

Hossain, M., D. A. Smith and R. E. C. Nordin: Parathyroid activity and post menopausal osteoporosis. Lancet 1: 809-811 (1970).

Krempien, B.: Bone medelling processes at the endosteal surface of human femora. Virchow Arch. A Pathol. Anat. Histol. 382: 73-88 (1979).

McGuire, J. L. and S. L. Marks. Jr.: The effects of parathyroid hormone on bone cell structure and function. Clin. Orthop. 100: 392-405 (1974).

Orimo, H., T. Fujita and M. Yoshikawa: Increased sensitivity of bone to parathyroid hormone in ovariectomized rats. Endocrinology 90: 760-763 (1972).

Parfitt, A. M.: The actions of parathyroid hormone on bone: relation to bone remodeling and turnover, calcium homeostasis, and metabolic bone disease. I. Mechanisms of calcium transfer between blood and bone and their cellular basis: morphological and kinetic approaches to bone turnover. II. PTH and bone cells: bone turnover and plasma calcium regulation. III. PTH and osteoclasts, bone loss, and the state of the bones in primary hyperparathyroidism. IV. The state of the bones in uremic hyperparathyroidism-the mechanisms of skeletal resistance to PTH in renal failure and pseudohypoparathyroidism and the role of PTH in osteoporosis, osteopetrosis, and osteofluorosis. Metabolism 25: 809-844, 909-955, 1033-1069, 1157-1188 (1976a-d).

Reifenstein, E. C., Jr.: The relationship of steroid hormones to the development and the management of osteoporosis in aging people. Clin. Orthop. 10: 206-257 (1957).

Saville, P. D.: Changes in skeletal mass and fragility with castration in the rat: A model of osteoporosis. J. Amer. Geriatrics Soc. 17: 155-166 (1969).

Simmons, D. J.: Cellular changes in the bones of mice as studies with tritiated thymidine and the effects of oestrogen. Clin. Orthop. 26: 176-189 (1963).

: Collagen formation and endochondral ossification in estrogen treated mice. Proc. Soc. exp. Biol. Med. 121: 1165-1168 (1966).

Storey, E.: The influence of adrenal cortical hormones on bone formation and resorption. Clin. Orthop. 30: 197-217 (1963).

Tatevossian, A.: Effect of parathyroid extract on blood calcium and osteoclast count in mice. Calcif. Tiss. Res. 11: 251-257 (1973).

Wink, C. S. and W. J. L. Felts : Effects of castration on bone structure of male rats: A model of osteoporosis. Calcif. Tiss. Int. 32: 77-82 (1980).

阿部和厚

T060 札幌市北区北15条西 7 丁目

北海道大学医学部

解剖学第三講座
Dr. Kazuhiro ABE

Department of Anatomy

Hokkaido University School of Medicine

Sapporo, 060 Japan 